\title{
Preliminary Phytochemical and Antimicrobial Activity Screening of Crude Extracts of Bird lime (Tapinanthus globiferus)
}

\section{1*EMAIKWU, V; ${ }^{1}$ NDUKWE, IG; ${ }^{1}$ IYUN, ORA; ${ }^{2}$ ANYAM, JV}

\author{
${ }^{* 1}$ Department of Chemistry, Ahmadu Bello University, Zaria, Nigeria \\ ${ }^{2}$ Department of chemistry, University of Agriculture, Markurdi, Nigeria \\ *Corresponding Author Email: emaikwuvictor@gmail.com
}

\begin{abstract}
Several species of the genus Tapinanthus have folkloric use by the Hausa and Fulani tribes of the Northern Nigeria as a remedy for numerous human and animal ailments including stomach ache, diarrhea, dysentery, wounds and swellings. The preliminary phytochemical screening of the stem bark of Tapinanthus globiferus, was carried out using standard method. The result of the phytochemical screening of crude ethylacetate, n-hexane extract revealed the presence of carbohydrate, flavonoids steroids and terpenes. The antimicrobial screening against Candida krusei, methicillin resistant Staphylococcus aureus, Campylobacter jejuni, Streptococcus pyogenes, vancomycin resistant enterococci, Helicobacter pylori, Escherichia coli, Shigella dysenteriae, Staphylococcus aureus and Candida tropicalis was done using agar well diffusion method. The zone of inhibition of growth of microorganisms ranged from $22-28 \mathrm{~mm}$ for the ethylacetate extract, and $18-21 \mathrm{~mm}$ for the $\mathrm{n}$-hexane extract and the minimum inhibitory concentration of the extracts was found to be between $0.63 \mathrm{mg} / \mathrm{ml}$ and $20 \mathrm{mg} / \mathrm{ml}$ while the minimum bactericidal/fungicidal concentration were found to be between $0.63 \mathrm{mg} / \mathrm{ml}$ and $20 \mathrm{mg} / \mathrm{ml}$. This research has establish a baseline information on the efficacy of the crude extracts of Tapinanthus globiferus.
\end{abstract}

\section{DOI: https://dx.doi.org/10.4314/jasem.v23i2.16}

Copyright: Copyright (C) 2019 Emaikwu et al. This is an open access article distributed under the Creative Commons Attribution License (CCL), which permits unrestricted use, distribution, and reproduction in any medium, provided the original work is properly cited.

Dates: Received: 16 December 2018; Revised: 20 January 2019; Accepted 29 January 2019

Keywords: Tapinanthus globiferus, alkaloids, flavonoids, antimicrobial screening, mistletoe

Mistletoes are often described as hemiparasites because they are partial parasites on various host, most of which are of economic value. They are partially parasitic in the sense, that though they are attached to the host plant from which they obtain nutrients and water, they have green leaves which carry out photosynthesis and thus manufacture food for the plant. Mistletoes of the Loranthaceae and Viscaceae, are widely used in various cultures in almost every continent to treat various ailments including hypertension, cancer, and diabetes, or used as a diuretic agent (Burkil, 2000; Sher and Alyemani, 2011; Jadhav et al., 2010). Tapinanthus globiferus is a mistletoe of the family Loranthaceae. It grows parasitically on trees and shrubs, nearly all the Loranthaceae family grow in the tropics. It is a woody, spreading shrub with blackish, smooth stems made rough by the presence of lenticels, the leaves are opposite but sometimes alternate. Literature search on the plant reveals the previous studies conducted which includes antibacterial effect (Ndukwe et al., 2001) antioxidant effect (Cook et al., 1998) and antihypertensive studies via reduction of LDL and triglycerides. It was also reported that the leaf decoction from this plant group is used for treating epilepsy and helps to calm electrical activities of the brain (Dazeel, 1938; Irvine, 1961). The objective of this paper is to report the preliminary phytochemical and antimicrobial activity screening of crude extracts of bird lime (Tapinanthus globiferus)

\section{MATERIALS AND METHODS}

Plant collection: Fresh stem samples of Tapinanthus globiferus growing on Terminalia catappa were collected from Samara in Zaria, Nigeria, in the month of July-August 2017 and sundried, the sundried stem was pulverized using mortar and pestle.

Extraction: $500 \mathrm{~g}$ of the pulverized stem was measured into a clean Winchester bottle and 1.5 liters of hexane was introduced and shaken intermittently and then filtered after 48 hours, the same was repeated for ethylacetate. Extracts were concentrated to one third of the original volume in vacuo using a rotary evaporator at about $42^{\circ} \mathrm{C}$, this yielded $1.2 \mathrm{~g}$ $(0.24 \%)$ of crude $\mathrm{n}$ - hexane extract, $1.2 \mathrm{~g}(0.24 \%)$ of crude ethylacetate extract and $2.5 \mathrm{~g}(0.5 \%)$ of methanol extract. These were then subjected to bioassay studies. 
Phytochemical screening: this was carried out on the pulverized plant sample to test for the presence of secondary metabolites using standard techniques (Brain et al., 1975) for carbohydrates, alkaloids, tannins, saponins, flavonoids, steroids and triterpenes.

Test organisms: Candida krusei, Methicillin Resistant Staphylococcus aureus, Campylobacter jejuni, Streptococcus pyogenes, Vancomycin Resistant enterococci, Helicobacter pylori, Escherichia coli, Shigella dysenteriae, Staphylococcus aureus and Candida tropicalis were used as the test organisms.

Antimicrobial activity screening: The antimicrobial activity tests of the extracts were carried out using some pathogens. The pure clinical bacterial and fungi isolate of vancomycin resistant enterococci, Helicobacter pylori, Escherichia coli, Shigella dysenteriae, Staphylococcus aureus, Candida tropicalis, of Candida krusei, methicillin resistant Staphylococcus aureus, Campylobacter jejuni and Streptococcus pyogenes were obtained from the department of medicinal microbiology, Ahmadu Bello University Teaching Hospital Zaria.

All the microbes were screened for purity and maintained in slants of nutrient agar for bacteria and slants of Sabouroud dextrose agar for fungi. In determining the antibacterial activities of the extracts, well diffusion method was used. The stock solutions of the plant extract was made by weighing $0.2 \mathrm{~g}$ of each extracts and dissolving in $10 \mathrm{ml}$ of dimethylsuphoxide (DMSO) to obtain a concentration of $20 \mathrm{mg} / \mathrm{mL}$ this was the initial concentration. This was also done for each of the extracts. Concentrations of $10 \mathrm{mg} / \mathrm{mL}, 5 \mathrm{mg} / \mathrm{ml}, 2.5$ $\mathrm{mg} / \mathrm{ml}, 1.25 \mathrm{mg} / \mathrm{ml}$ and $0.63 \mathrm{mg} / \mathrm{ml}$ were prepared, and the media prepared above was inoculated with $0.1 \mathrm{~mL}$ standard inocula of the test organisms. The inocula were spread evenly over the surface of the medium by the use of a sterile swab.

The agar plates were seeded with $0.1 \mathrm{ml}$ of the standard inoculum of the test microbe. Inoculation was made at $37^{\circ} \mathrm{C}$ for 24 hours. Standard cork borer of $6 \mathrm{~mm}$ diameter was used to cut a well at the center of each inoculated medium and $0.1 \mathrm{~mL}$ of the solution of the extracts of the concentration of $20 \mathrm{mg} / \mathrm{ml}$ was introduced into the well on the inoculated medium, the plates were then incubated at $37^{\circ} \mathrm{C}$ for 24 hours for the bacteria and at $25^{\circ} \mathrm{C}$ for the fungi. They were observed after the periods of incubation as to note the zone of inhibition of growth. The zones were recorded in millimeters of their diametrical section as shown table 3. The minimum inhibitory concentration of the extracts was carried out on the test organisms using the broth dilution method. Muller-Hinton broth was prepared according to the manufacturers guidelines. Mac-farlands turbidity scale number 0.5 was prepared and $10 \mathrm{ml}$ was dispensed into sterile test tubes and the test microbes were then inoculated and incubated at $37^{\circ} \mathrm{C}$ for 6 hours. Dilution of the test microorganisms in the in the normal saline was performed until the turbidity marched that of the Mac-farlands scale by visual comparison, at this point the microorganisms had a concentration of about $1.5 \times 10^{8} \mathrm{cfu} / \mathrm{ml}$. Two fold serial dilution of the extracts in the broth were performed to obtain the concentration of $20 \mathrm{mg} / \mathrm{ml}, 5$ $\mathrm{mg} / \mathrm{ml}, 2.5 \mathrm{mg} / \mathrm{ml}, 1.25 \mathrm{mg} / \mathrm{ml}$, and $0.63 \mathrm{mg} / \mathrm{ml}$ respectively, the initial concentration was obtained by dissolving $0.2 \mathrm{~g}$ of the extracts in $10 \mathrm{ml}$ of the sterile broth. Having obtained the different concentration of the extracts in the sterile broth, $0.1 \mathrm{ml}$ of the standard inoculum of the test microorganism in the normal saline was then inoculated into the different concentration incubation was carried out at $37^{\circ} \mathrm{C}$ for 24 hours after which each broth was observed for turbidity. The lowest concentration of the extract in the broth which showed no turbidity was recorded as the minimum inhibitory concentration recorded for the various microbes (Table 4.)

\section{RESULTS AND DISCUSSION}

Phytochemical screening: the preliminary phytochemical screening of the extracts of Tapinanthus globiferus showed the presence of carbohydrates, alkaloids and steroids in the hexane, ethylacetate and methanol extracts, flavonoids and triterpenes were present in both ethylacetate and methanol extracts, while cardiac glycosides and anthraquinones where present only in the methanol extracts. The results obtained in this screening are shown in table 1.

Table 1: Result of phytochemical screening

\begin{tabular}{lllll}
\hline S/N & $\begin{array}{l}\text { Phytochemical } \\
\text { constituents/test }\end{array}$ & EA HE & ME \\
\hline 1 & Carbohydrates & + & + & + \\
2 & Alkaloids & + & + & + \\
3 & Tannins & - & - & + \\
4 & saponins & - & - & - \\
5 & Flavonoids & + & - & + \\
6 & Stercids & + & + & + \\
7 & Triterpenes & + & - & + \\
8 & Cardiac glycosides & - & - & + \\
9 & Anthraquinones & - & - & + \\
\hline
\end{tabular}

Key: + = present, - = absent $\mathrm{HE}=$ Hexane extract, EA = ethyl acetate extract, $\mathrm{ME}=$ methanol extract 
Table 2: Results of the antimicrobial screening of the crude extracts

\begin{tabular}{|c|c|c|c|c|c|c|}
\hline Test organisms & \multicolumn{6}{|c|}{ EA HE ME CP SP FLU } \\
\hline Methicillin-resis tant S tophylococcus aureus & $R$ & $\bar{R}$ & $\mathrm{R}$ & $\mathrm{R}$ & & \\
\hline Vancomycin resistant enterococci & S & S & S & s & & \\
\hline anvers & S & S & S & s & & \\
\hline pyogenes & $\mathrm{R}$ & $\mathrm{R}$ & $\mathrm{R}$ & s & & \\
\hline Escherichia coli & S & \$ & S & S & & $\mathbb{R}$ \\
\hline Campvlobacter j jivi & R & $\mathrm{R}$ & $\mathrm{R}$ & S & & $\mathrm{R}$ \\
\hline Helicobacter pvlori & \$ & s & s & $\mathrm{R}$ & & \\
\hline Shigella dus enteriae & \$ & s & $\mathrm{R}$ & \$ & & $\mathrm{R}$ \\
\hline Candida krusei & $\mathrm{R}$ & $\mathrm{R}$ & s & $\mathbf{R}$ & & S \\
\hline Candida tropicalis & s & S & s & $\mathrm{R}$ & & S \\
\hline
\end{tabular}

Key: $S=$ Sensitive, $R=$ Resistance, $H E=$ Hexane extract, $E A=$ ethyl acetate extract, $M E=$ Methanol extract

Table 3: Zone of inhibition of the test organism by the extracts $(\mathrm{mm})$

\begin{tabular}{|c|c|c|c|c|c|c|}
\hline Test org anism & EA & $\mathrm{HE}$ & ME & $\mathrm{CP}$ & SP & FLU \\
\hline Methicillin-resistant stophylococcus aureus & & 0 & 0 & 0 & 30 & 0 \\
\hline Vancomycin resistant enterococci & 25 & 20 & 23 & 32 & 0 & . \\
\hline Staphlococcus aureus & 28 & 21 & 25 & 35 & 32 & 0 \\
\hline Streptococcus pyogenes & 0 & 0 & 0 & 32 & 0 & 0 \\
\hline Escherichia coli & 23 & 18 & 21 & 38 & 35 & 0 \\
\hline Campulobacter jejuni & 0 & 0 & 0 & 31 & 0 & 0 \\
\hline Helicobacter pulori & 22 & 18 & 20 & 0 & 30 & 0 \\
\hline Shigella dus enterias & 27 & 20 & 0 & 38 & 37 & 0 \\
\hline Candida krusei & 0 & 0 & 22 & 0 & 0 & 35 \\
\hline Candida tropicalis & 24 & 20 & 24 & 0 & 0 & \\
\hline
\end{tabular}

Key; $H E=$ Hexane extract, $E A=$ ethyl acetate extract, $M E=$ Methanol extract; $C I P=$ ciprofloxacin, $S P=$ sparfloxacin, $F L U=$ fluconazole

Table 4: Determination of MIC MBC/MFC of the extracts on test organism

\begin{tabular}{|c|c|c|c|c|c|c|}
\hline Test organisms; & MIC & & $\mathrm{g} / \mathrm{mL})$ & $\mathrm{MBC}$ & MFC & $(\mathrm{mg} / \mathrm{mL})$ \\
\hline & & & $\mathbb{M E}$ & $\mathrm{HE}$ & & \\
\hline $\mathrm{V}$ anc omycin resis tant enterococoi & 5 & 2.5 & $\overline{12.5}$ & 20 & 10 & 25 \\
\hline Staphlococcus aureus & 5 & 1.25 & 6.25 & 20 & 5 & 25 \\
\hline $\begin{array}{l}\text { Streptococcus pvogenes } \\
\text { Escherichia coli }\end{array}$ & 10 & 5 & 12.5 & 20 & 10 & 50 \\
\hline Campul obacter jejuni & - & . & . & & & - \\
\hline Helicobacter pulori & 10 & 5 & 12.5 & 20 & 20 & 50 \\
\hline Shigella dus enterias & 5 & 2.5 & 12.5 & 20 & 5 & 25 \\
\hline Candida krusei & - & - & - & - & - & - \\
\hline Candida tropicalis & 5 & 5 & 12.5 & 20 & 10 & 50 \\
\hline
\end{tabular}

Key; $H E=$ Hexane extract, $E A=$ ethyl acetate extract, $M E=$ Methanol extract; $M I C=$ minimum inhibitory concentration, $M B C / M F C=$ minimum bactericidal concentration $/$ minimum fungicidal concentration

The result of antimicrobial activity of the n-hexane, ethylacetate and methanol fractions showed inactivity to methicillin resistant staphylococcus aureus, streptococcus pyogenes and campylobacter jejuni and active on vancomycin resistant Enterococci, Staphylococcus aureus, Escherichia coli, Helicobacter pyroli, Shigella dysenteriae and Candida tropicalis with zones of inhibition on the microbes for the n-hexane extract to be $20,21,18$, $18,20,20 \mathrm{~mm}$ respectively. However the ethylacetate extract showed a higher zone of inhibition than that of n-hexane extract having the following values of $25,28,23,22,27$ and $24 \mathrm{~mm}$. The highest was recorded on Staphylococcus aureus to be 28 and the lowest at $22 \mathrm{~mm}$ on Helicobacter pyroli. The methanol fraction showed zones of inhibition at 23, $25,21,20,22,24 \mathrm{~mm}$ having the highest zone of inhibition to be $25 \mathrm{~m}$ staphylococcus aureus. Table 3 . Showed the zone of inhibition of the three extracts against the test organisms. The ethylacetate extract shows the more toxicity on the test organisms than the hexane and methanol extract. The extracts are rather bacteriostatic to the test organisms.

The result of the minimum inhibitory concentration of the ethylacetate extract revealed that the extract could inhibit the growth of Escherichia coli, Helicobacter pyroli and Candida tropicalis at a concentration of $5 \mathrm{mg} / \mathrm{ml}$, it could also inhibit the growth of vancomycin resistant Enterococci and Shigella dysenteriae at a concentration of $2.5 \mathrm{mg} / \mathrm{ml}$ and could also inhibit the growth of Staphylococcus aureus at a concentration of $1.25 \mathrm{mg} / \mathrm{ml}$. The result of the minimum inhibitory concentration of the hexane extract revealed that the extracts could inhibit the growths of vancomycin resistant enterococci. Staphylococcus aureus, Shigella dysenteriae, and Candida tropicalis at a concentration of $5 \mathrm{mg} / \mathrm{ml}$, it could also inhibit the growth of Escherichia coli and Helicobacter pyroli at a concentration of $10 \mathrm{mg} / \mathrm{ml}$.

Conclusion: From the overall results of the analysis, the zone of inhibition produced by the ethylacetate and $n$-hexane extract on these organisms compared fairly well with the zones of inhibition produced by Ciprofloxacin and Sparfloxacin and Fluconazole. Which are regular drugs used internationally for the treatment of disease associated with these microbes. These therefore establish the ethnomedicinal claims.

\section{REFERENCES}

Brain, KR and Turner, TD (1975). The Practical Evaluation of Phytopharmaceutical pp.5763, wright Science Technical Bristol,

Burkill, HM (2000). Useful Plants of West Tropical Africa, 2nd edition Royal Botanic Gardens, New England 5: 548-560

Cook, JA; Van der Jagt, DJ; Dasgupta, A; Mounkaila, G; Glew, RS et al. (1998). Use of the Trolox assay to estimate the antioxidant content of seventeen edible wild plants of Niger. Life Sci 63: 105-110.

Daziel, JM (1937). The Useful Plants of West Africa, vol.1, p.237, crown agents colonies, London.

Irvine, R (1961). Woody Plants of Ghana, pp.476479, oxford university press, London. 
Jadhav, N; Patil, CR; Chaudhari, KB; Wagh, JP; Surana, SJ et al. (2010). Diuretic and natriuretic activity of two mistletoes species in rats. Pharmacognosy Res 2: 50-57.

Ndukwe, IG; Amupitan, JO; Ashonibare, OE (2001). Phytochemical analysis and antimicrobial activity screening of the crude extracts from the aerial parts of Tapinanthus globiferus. Nig. J. Chem. Res 6: 43-46.
Sher, H; Alyemeni, MN (2011). Pharmaceutically important plants used in traditional system of Arab medicine for the treatment of livestock ailments in the kingdom of Saudi Arabia. Afr. J. Biotechnol. 10: 9153-9159. 